\title{
Exploration and Practice of Network Teaching Mode in Colleges and Universities in the Era of Omnimedia
}

\author{
Haoyu $\mathrm{Wu}^{1, *}$ \\ ${ }^{1}$ Guangzhou Civil Aviation College, Guangzhou, Guangdong, China \\ *Corresponding author. Email:9681126@qq.com

\begin{abstract}
With the continuous development and popularization of network technology, multi-screen applications based on smart network terminals such as mobile phones and tablets have become an important method of information transmission. The deep integration of traditional media, micro media and new media has shaped the form of omnimedia. The non-formal education mode such as online education leads the reform of online teaching mode in colleges and universities. Colleges and universities should adapt to the social development, innovate the teaching mode, instead of blindly following the trend. They should design effective network teaching mode based on the significance of implementing network teaching mode and the challenges faced by traditional education mode in colleges and universities in the omnimedia era.
\end{abstract}

Keywords: the era of omnimedia, colleges and universities, network teaching mode

\section{INTRODUCTION}

In the 21 st century, as the era of rapid development and progress of network information, the continuous development of network technology, information technology and communication technology has brought far-reaching influence to the people's access to information channels, work, life, study and social communication. The society has also stepped into the digital society, which is the digitalization of various forms of information communication. The information content is three-dimensional and omni-directional in various forms such as sound, text and image. Different types of media are constantly integrating, grafting and transforming, involving not only the traditional media such as TV, newspaper, radio and periodical, but also the new media such as digital TV, Internet and mobile phone. This symbolizes the arrival of the omnimedia era. In recent years, the mode of online education in colleges and universities has been continuously deepened and extended, providing technical support for the development of online teaching in colleges and universities in China. The implementation of network education mode really makes up for the shortcomings of the previous education mode of simple knowledge explanation, further optimize and adjust the teaching mode, deeply fit the needs of current quality education, and thus truly present the promotion effect of network education mode on the development of China's higher education.

\section{CORE CONCEPT DEFINITION}

\section{A. The concept of omnimedia}

The concept of omnimedia has been put forward by the media industry for more than ten years, and the theoretical circle has been exploring its deep connotation on the basis of industry practice. However, the theoretical circle has not yet formed a unified definition of the concept of omnimedia. This study mainly expounds three types widely recognized by scholars. The first is the theory of communication forms. In this view, omnimedia is the specific combination of many media forms, with the characteristics of comprehensiveness and diversity. Omnimedia, as a new form of media with qualitative changes after the integration of traditional media and new media, continues to be inclusive with the development of communication technology and information technology in the specific development process, reflecting the form of comprehensiveness and openness. Generally speaking, the form of communication is more consistent with the omnimedia connotation. The second is the integrated application theory. In terms of this theory, the relevant scholars clearly indicated that omnimedia has the characteristics of multimedia, conformability and integration. This view holds that media carriers used in every link of communication activities should be effectively integrated from the perspectives of production, operation and communication. The third is the theory of media operations and marketing. This view indicates that omnimedia has the characteristics of media 
information production fusion and media form fusion, which is a diversified and cooperative information marketing communication method based on rich and diversified media

\section{B. The concept of network teaching mode}

Teaching in the network environment generates the framework of a relatively stable relationship and activity process between teachers and students, taking the network as the supporting environment for the implementation of education. The network teaching mode highlights the key role and status of the network in the educational activities of teachers and students. The network teaching mode with reasonable and scientific structure can not only maximize the advantages of the network, but also effectively improve the learning effect of students. The main characteristics of network teaching model are reflected in the role of teachers, the role of media, the status of students and the educational process, etc. The definition of network teaching mode refers to the distance cooperative learning mode based on the Internet. It is to implement distance interactive learning and education with the help of high-quality teachers in colleges and universities and multimedia network. This teaching model can get rid of the shackles of time and place. The implementation of this model depends on a number of factors, such as remote networking systems, school support, and the formation of study groups. Many universities in various regions have successively established cooperative learning groups, and based on the same theme, implemented cooperative education and learning activities such as problem discussion, method exchange and work evaluation under the support of distance websites.

\section{THE SIGNIFICANCE OF NETWORK TEACHING MODE IN UNIVERSITIES IN THE OMNIMEDIA ERA}

\section{A. Effectively broadening the access to knowledge of college students}

Network technology itself has strong advantages of resource sharing and openness, which continuously improve the practice efficiency and effect of network teaching mode in colleges and universities. In the era of omnimedia era, information transmission is changing with each passing day, and the network platform contains a large number of information resources. With the constant change of the needs of students in colleges and universities for knowledge, individuals can effectively acquire the knowledge they require through the network teaching mode. At the same time, in the process of receiving relevant knowledge education, students can grasp basic social development trends through network teaching mode, extend individual knowledge scope and perspective, and play a certain role in promoting the growth and development of college students. The application of network teaching mode in innovation promotes the online education in colleges and universities to be more open. Students can receive and learn knowledge through many channels in the network education environment, so as to enrich their own knowledge system and improve their comprehensive ability.

\section{B. Promoting effective knowledge sharing between teachers and students}

The sharing and openness of information resources on the Internet enable colleges and universities to make full use of online education resources. As an innovative and significant information source, the online education in colleges and universities plays a very similar educational role with the university library. However, the online teaching mode in colleges and universities does not require most of the space inside the campus. It is true that in recent years, the network teaching mode has been widely and universally applied in the education of colleges and universities in the course of social informatization and digitization, which further promotes the in-depth development of the network teaching in colleges and universities in China. With the continuous innovation and reform of network teaching mode, colleges and universities have become network teaching modes such as distance education and interactive education in the digital age, which also urges teachers and students to get rid of the constraints of time and space, and make use of the network as a means of distance and online teaching. Therefore, the rational use of network teaching mode in colleges and universities can provide information resource sharing and knowledge interaction platform for the work of network education in colleges and universities. With the strong support of education and research network, it will further promote the informationization development of national higher education.

\section{Rapid and diversified learning styles of students}

In the age of omnimedia, the traditional teaching mode has its drawbacks. Educational activities and teaching means are mainly completed through textbooks and effective interactions between students and teachers; the form of knowledge received by student groups is relatively simple, and the content of knowledge is generally theorized. Therefore, it is impossible to cultivate the innovative consciousness, ability and spirit of college students through this mode of education. For example, when college students have questions about practical problems and ask questions, they need to wait enough time for the teacher to give specific answers. Generally speaking, for China's domestic higher education, a teacher often has to face dozens or even hundreds of college students, and the 
time for teachers to answer students' various questions is not enough. As a result, the previous teaching model mainly focuses on teachers' active analysis of knowledge and related problems, and generally adopts a single teaching method of knowledge infusion in class. This infusion teaching mode has negative effects on students' learning enthusiasm and initiative. However, using the network teaching mode, students can use the online teaching platform to communicate with teachers and students, or retrieve the knowledge resources needed according to what they learn in class. This effectively promotes the rapid and diversified learning methods of students, and provides convenient and fast conditions for college students to learn knowledge enrich themselves and improve their comprehensive abilities in the omnimedia era. It really promotes students to acquire information and learn knowledge, and finally develops comprehensively under the environment of network teaching in colleges and universities.

\section{Challenges FaCED BY TRAditional EDUCATION MODES IN UNIVERSITIES IN THE OMNIMEDIA ERA}

\section{A. Changes in schema types and programs}

The typical representative of the traditional education mode is the six-link comprehensive education mode put forward by Kerloff, which includes the six links of teachers organizing teaching activities, revising the existing knowledge, introducing new lesson content, explaining knowledge of the new lesson, consolidate knowledge in the new lesson and assigning homework after class. The main characteristic of this teaching mode is that the teacher at the center of the class, takes the teaching discourse and blackboard writing as teaching means, teach the textbook knowledge to the class students, and the students are passive, unified and unidirectional to accept the content taught by the teacher. This teaching mode, which has occupied an important position in the education circle for several years, takes the teacher as the teaching center, carries out teaching and learning in the classroom, attaches importance to teaching methods, teaching tools and teacher-student interaction. Admittedly, this traditional education model has been criticized by many scholars and educators because it can hardly cultivate qualified talents with advanced thinking and practical problem solving abilities, but only to make students who are obedient and have superficial understanding of knowledge. At present, with the arrival of the omnimedia era and the development of modern technology based on network technology and multimedia computer, new educational models have been born. For example, Professor Li Dongke has mentioned the cooperative learning model based on the campus network environment, the internet-centered group cooperative distance learning model and the independent learning model based on the function of the subject website, etc. And Professor He Kekang proposed the online teaching modes include lecturing, collaboration, individual tutoring and inquiry. It is precisely the birth of the network teaching regarding students as the main body of teaching activities that brings great challenges to the traditional education in colleges and universities.

\section{B. Changes in the educational environment}

From the perspective of traditional educational environment, educational environment refers to student learning places composed of campus buildings, libraries, classrooms, laboratories and learning areas at home. Generally speaking, in the subjective consciousness, the traditional educational environment is usually composed of classroom, blackboard, platform and chalk. This educational environment is characterized by immobilization and statics without necessary changes. However, the educational environment in the omnimedia era refers to a multidimensional environmental system with control and restraint functions for the occurrence and development of educational activities. In the educational activities in the omnimedia era, network technology provides and creates a rich and colorful educational environment for subject teaching. Network multimedia classroom, Internet, campus network, electronic reading room and computer network classroom have all become the new contents of the reconstruction of college education environment in the omnimedia era. The new educational environment system realizes the interaction of information resources through diversified ways and external environment, and provides a better self-study environment for college students objectively.

\section{Changes in the role of teaching media}

The so-called teaching media refers to the intermediary and carrier that spread educational information resources in the process of education. On the basis of educators' teaching discourse, the original teaching media appropriately add some simplified media resources in order to realize richer and more diversified information transmission. Such resources can be textbooks, pictures, blackboards, picture books, objects and models for example, which have significant disadvantage in terms of visualization, knowledge and information display. Constrained by the level of technological development, it is impossible for the traditional teaching media to create vivid and lively teaching situations in the classroom. Meanwhile, limited by time and space, it is difficult for them to deliver massive information contents in the classroom. In addition, in terms of knowledge resource expression, compared with the teaching media in the omnimedia era, the traditional teaching media are too rigid and 
monotonous to arouse students' enthusiasm for learning. With the development of information technology, network technology and the coming of omnimedia era, the traditional teaching media has gradually changed in the direction of information-based teaching media. New teaching media have advantages and characteristics that traditional teaching media do not have. Setting text, sound, image and other functions as one, they provide vivid picture and pleasant music, stimulate students' various senses to the greatest extent, and create a vivid, lively situation for classroom teaching and help students actively explore and discover the content delivered by the teacher.

\section{PRACTICAL EXPLORATION OF NETWORK TEACHING MODE IN COLLEGES AND UNIVERSITIES IN THE OMNIMEDIA ERA}

\section{A. Online individual coaching-based education model}

In the age of omnimedia, the online individual coaching-based education model refers to the teaching work that regards individual characteristics as the focus, takes individual development as the main goal and serving the society as the end result, conforms to individual needs as the criterion, and regards students' independent learning and self-management as the main form of activities. The characteristic of individualized education mode is that it takes students as the teaching center, and the teaching section covers electronic textbooks, homework, blogs, emails, chatting and management. In the network education system, individual tutoring education mode can be realized by using two forms of CAI software and E-mail between teachers and students in the self-learning software library and audio resource library. First, the teacher sends CAI software, including educational objectives, educational content, problem solving, and educational key and difficult points to the network for students to read and download freely. At the same time, students can adjust the learning difficulty and progress according to the individual learning level and ability, carry out targeted learning, and then realize individual tutoring teaching based on independent learning. The individualized teaching environment generated by CAI software not only relieves the pressure of teachers' education, but also enables each student to carry out selective learning according to individual conditions. The second is to achieve individual counseling education with the help of virtual network in the E-mail and interactive conversation. The advantage of this model is that students can get the real-time analysis of a certain knowledge point from the teacher, just like the two being face to face, but it requires teachers and students to access the network at the same time. When students encounter difficulties, they can ask teachers for help through E-mail or online conversation, and the teachers will give answers according to the questions raised by the students and help them solve their doubts. In this way, the common needs of all students and the individual problems can be balanced.

\section{B. The teaching mode of network cooperation and sharing}

The teaching mode of network cooperation and sharing refers to the continuously derived teaching mode which is based on the individual teaching mode and the lecturing teaching mode.. To be more specific, it refers to that teachers complete teaching tasks and educational activities in cooperation and communication with many students in different areas or in multimedia classrooms by means of computer network, multimedia and other related technologies Teachers should guide students to organize cooperative learning partners according to the theme of cooperative learning by means of network communication tools, discuss and design cooperative learning plans, discuss knowledge, and carry out cooperative learning activities, so as to complete the tasks assigned by teachers and fully understand and master the content taught by teachers. Compared with the education mode of individual counseling, the education mode of network cooperation and sharing is more conducive to promoting the development of advanced cognitive ability and level of students, as well as the generation of students' positive emotions and attitudes. Cooperative and shared teaching model regards group as a cognitive system, which focuses on the interaction between individuals, others and the environment rather than individual contributions, and is also a shared expression built by groups. Cooperative sharing teaching is effective because students are learning interactive thinking in this environment. The specific educational process of this teaching mode includes reviewing the previous learning content and deepening the understanding of knowledge, first of all. With the help of the Internet retrieval of relevant knowledge, students improve their own habits of information retrieval to find answers. Secondly, according to the content of the textbook, relevant resources are retrieved and corresponding pictures and text research content is combined to design a web page with both pictures and text. The third is to make clear the teaching theme. Students choose the topic according to individual understanding, and ask corresponding questions. Fourthly, members in the group communicated with each other and are bold to express their own ideas. Fifth, the whole group together makes a summary of the learning content and carry out effective communication. According to the questions given, the students have a reasonable division of labor to consult the materials, exchange and share the materials with each other, and use the form of division of labor cooperation to complete the learning tasks within the group. The last is to make integral analysis and recognition of 
achievements. Teachers should evaluate the learning outcomes of each group and encourage and affirm the students. The obvious characteristic of network cooperation and sharing education mode is that it pays attention to the cultivation of students' practical level and ability. Only in specific time can their innovation consciousness be translated into innovation ability.

\section{Network self-inquiry teaching mode}

In the network self-inquiry teaching mode, teachers generally put forward practical problems suitable for students to solve, and release them to students through campus network to guide them to solve the problems and carry out thematic inquiry learning. At the same time, this mode provides massive and problem-related teaching resources for students to refer to during problem solving. Students can learn from the terminals connected with the computer equipment in the same center, and teachers can use computers to organize online education activities according to the feedback of each student on teaching work, adjust the teaching progress, clarify students' learning needs, and provide them with suitable teaching materials and teaching contents. The technology fully realized by the network self-inquiry education mode is relatively simple and low in price, and has strong practicability. Specific links of independent inquiry teaching include: independent learning, discovering problems, clarifying teaching themes, searching materials, simplifying viewpoints, drawing conclusions, interactive communication, mutual evaluation and feedback. The use of this teaching mode can help students to improve their self-learning ability, get used to the application of network learning tools, and adapt to the new teaching mode in the omnimedia era.

\section{CONCLUSION}

To sum up, the continuous development of network technology and the deep integration of media forms make the network teaching mode emerge at the historic moment, and colleges and universities therefore usher in the in-depth reform of teaching work. The reform and innovation of network teaching mode can effectively promote the sustainable development of network education in colleges and universities, provide a platform for students to share information resources and exchange knowledge in the future, and make the ways for students to obtain information resources more rapid and diversified. Against this background, educators in colleges and universities should enhance their scientific cognition of network education, explore practical strategies of network teaching mode, and actively promote the modernization of national education.

\section{References}

[1] Lei Xia, Cheng Qionghui, Wang Duan, Lu Yuangang, Wu Jinjin. Establishment and practice of internet teaching in dermatology and venerology $[\mathrm{J}]$. Chinese Journal of Medical Education Research, 2013(04): 430-432. (in Chinese)

[2] Fan Ying. Influence and Research of Innovation and Reform of Online Teaching Mode on Online Education in Chinese Universities [J]. Science and Technology Economic Market, 2016(03): 245+244. (in Chinese)

[3] Shen Zhipeng, Liang Jinshan, Zhang Ning. Network Teaching Mode Reform of Automation Major with Shipping Characteristics [J]. Education Forum, 2020(16): 135-136. (in Chinese)

[4] Wang Jin. Thinking on the Optimization Effect of Network Teaching Mode on Computer Basic Teaching in Higher Vocational Colleges [J]. Course Education Research, 2018(47) 211-212. (in Chinese)

[5] Li Binggan. Research on Computer Education And Teaching Innovation in Internet + Era Network Teaching Mode [A] Hebei Huatu Cultural Communication Co., LTD. Academic Proceedings of Multidisciplinary Integrated Education promoting the Development of Interdisciplinary Talents' Core Qualities [C]. Hebei Huatu Cultural Communication Co., LTD. 2019: 3. (in Chinese)

[6] Yu Wenjing. Practice and Innovation of College English Network Teaching Mode in ethnic Colleges [A]. Research on Development and Innovation of Foreign Language Education and Translation (Vol. 3) [C]. 2014: 4. (in Chinese) 